\title{
In Vitro Therapeutic Equivalence of Two Multisource (Generic) Formulations of Sodium Phenytoin (100 mg) Available in Peru
}

\author{
Angel T. Alvarado ${ }^{1 *}$, Ana Maria Muñoz ${ }^{1}$, Jessica M. Miyasato², Erick A. Alvarado², Berta Loja², Laura \\ Villanueva ${ }^{3}$, Mario Pineda ${ }^{3}$, Maria Bendezú4 ${ }^{4}$ Juan J. Palomino-Jhong ${ }^{4}$, and Jorge A. García ${ }^{4}$ \\ ${ }^{1}$ School of Human Medicine, San Ignacio de Loyola University, Lima, Peru. \\ ${ }^{2}$ Peruvian Association of Immunogenomics and Personalized Medicine, Lima, Peru. \\ ${ }^{3}$ Faculty of Pharmaceutical Sciences and Biochemistry, Inca Garcilaso de la Vega University, Lima, Peru. \\ ${ }^{4}$ Faculty of Pharmacy and Biochemistry, San Luis Gonzaga National University of Ica, Ica, Peru.
}

e-mail: eaa.alvarado@hotmail.com

\begin{abstract}
This in vitro study evaluated the therapeutic equivalence of two multisource (generic) formulations of 100-mg phenytoin as immediate-release tablets available in the Peruvian pharmaceutical market, compared with the reference medicine, to establish interchangeability. The mean weight, hardness, and content of active substance were evaluated, prior to analyzing the dissolution profile. USP dissolution apparatus 2 (paddle) was used at $75 \mathrm{rpm}$ with $900 \mathrm{~mL}$ of dissolution medium at $37 \pm 0.5^{\circ} \mathrm{C}$ at $\mathrm{pH}$ levels of $1.2,4.5$, and 6.8 . The generic and reference formulations had similar weight or drug content, but hardness values were significantly different $(p=0.029)$. At $\mathrm{pH} 1.2$, the generic products were considered therapeutically equivalent to the reference product based on similarity factor $\left(f_{2}\right)$ and dissolution efficiency values; however, at $\mathrm{pH} 4.5$ and 6.8 , there were differences in dissolution performance based on $f_{2}$ values below the acceptable range.
\end{abstract}

KEYWORDS: Phenytoin, dissolution, multisource medicine, therapeutic equivalence in vitro

\section{INTRODUCTION}

he quality of an oral solid pharmaceutical form is guaranteed by quality control tests such as the variability of weight, hardness, friability, and content of the active substance, and the performance of the medicine is guaranteed by analyzing the dissolution profile $(1,2)$. Dissolution is a kinetic process in which a solid dosage form dissolves in a dissolution medium, thereby releasing the drug within a specific amount of time (1). To demonstrate therapeutic equivalence, it is necessary to do bioequivalence studies in vitro and in vivo (i.e., relative bioavailability, pharmacodynamics, and clinical trials) (3-7). In vivo studies are performed when there are differences in bioequivalence that indicate a lack of therapeutic equivalence $(3,8)$.

In vitro bioequivalence studies are carried out between pharmaceutical equivalents (same dose, active ingredient, and route of administration), comparing the kinetic dissolution profiles of a multisource (generic) product with the reference. The same dissolution test is performed in three dissolution media at $\mathrm{pH} 1.2,4.5$, and
6.8 , which allows the interchangeability to be guaranteed in the clinic based on the bio-exemption criteria of the Biopharmaceutical Classification System (BSC) (1, 3, 6-7, $9,10)$. Results are then evaluated by two independent statistical models: the difference factor $\left(f_{1}\right)$ and similarity factor $\left(f_{2}\right)(4,7,9-11)$.

The difference factor measures the percentage of error between the two dissolution profiles in pre-established sampling times. An $f_{1}$ value of exactly zero indicates that the two profiles are equal; if the value is less than 15 , then the two profiles are similar, and if the value is greater than 15 , the profiles are different $(12,13)$. The similarity factor $\left(f_{2}\right)$, proposed by Moore and Flanner (the logarithmic transformation of the reciprocal of the square root of the sum of the squared errors), indicates the similarity between the dissolution profiles (14). The $f_{2}$ value is determined from the difference between the mean dissolution percentage between the generic drug and reference (13). An $f_{2}$ value of exactly 100 means that the profile of the generic drug is identical to the reference; if the value is $50-99$, then the profiles are similar $(10,12$, 
13), and in both cases, the profiles are considered to be bioequivalent in vitro. But, if the value is less than 50 , it indicates that there is at least a $10 \%$ difference in the curves (13).

Additionally, dissolution efficiency (DE) and average dissolution time are studied. DE describes the area under the dissolution curve (AUC) at a certain time point, expressed as a percentage of the rectangle described for $100 \%$ dissolution at the same time. DE must be greater than $50 \%$ for immediate-release medications. DE indicates the percentage of dissolved drug in the intestinal mucosa after a certain amount of time. The degree of absorption of a drug in vivo is proportional to the amount of drug dissolved in the dissolution medium. The mean dissolution time (MDT) is the residence time of the drug in the solid state within a solution $(1,12,15)$.

Phenytoin has a dissociation constant (pKa) value of 8.3, so it is absorbed in its non-ionized form at the stomach level ( $\mathrm{pH}$ of 1.5). This gives us the basis for establishing therapeutic equivalence in vitro in a pH 1.2 dissolution medium. Because phenytoin is a class 2 drug according to the Biopharmaceutical Classification System (BSC), a bioexemption can be done if the generic medication dissolves rapidly (at least $85 \%$ in $30 \mathrm{~min}$ ) and if the dissolution profile is similar to the reference medicine at $\mathrm{pH} 1.2$, 4.5, and 6.8. However, because phenytoin is a drug of narrow therapeutic scope, in vivo studies should always be considered to demonstrate its interchangeability $(6,16$, 17).

In the Hospitals of the Ministry of Health of Peru, phenytoin is prescribed in different oral dosage forms, such as 100 mg sodium phenytoin tablets, liquid phenytoin at 125 $\mathrm{mg} / 5 \mathrm{~mL}$, and parenteral sodium phenytoin at $50 \mathrm{mg} / \mathrm{mL}$ (18). In private pharmacies, the Epamin brand is available in $100 \mathrm{mg}$ capsules, but it cannot be used as a reference medicine for bioequivalence studies because the dosage form is different. Therefore, for the present study, we have acquired $100 \mathrm{mg}$ sodium phenytoin tablets for comparison.

The objective of this research was to determine the therapeutic equivalence by means of in vitro studies of two generic formulations of $100-\mathrm{mg}$ phenytoin immediate-release tablets available in the Peruvian pharmaceutical market, compared with the reference medicine, to establish interchangeability $(19,20)$. As a statistical indicator of equivalence, similarity factor, and DE were used.

\section{MATERIALS AND METHODS}

\section{Chemicals and Reagents}

A primary USP phenytoin standard was used, and all reagents were of analytical grade and quality (American Chemical Society), including $36 \%$ hydrochloric acid $(\mathrm{HCl})$, anhydrous sodium acetate, sodium hydroxide, potassium monobasic phosphate, and methanol. These reagents were purchased from Mercantil Laboratory SAC (Lima, Peru). Xtra PVDF-45/25 chromafil filters were used (0.45 $\mu \mathrm{m} / 25 \mathrm{~mm})$.

\section{Tablet Samples}

The study was analytical, experimental, and transversal. The study samples consisted of 200 tablets of the reference and generic products from the same (respective) batch. The reference product was $100-\mathrm{mg}$ sodium phenytoin tablets (bioequivalent LCh) (lot E0517, RS IPS $N^{\circ}$ F-1371-Chile, Chile Laboratory), purchased at the Cruz Verde Pharmacy in Santiago de Chile. The two generic products were $100-\mathrm{mg}$ sodium phenytoin tablets, labeled T-1 (lot E1017, RS EE00640, Laboratory Teva) and T-2 (lot E0416, RS EE-00640, Marfan Laboratory) and acquired from a drugstore and hospital pharmacy, respectively, in Lima, Peru.

\section{Quality Control Tests}

Quality control tests were performed to meet the quality criteria of USP and WHO $(2,14)$. For the hardness test, a sample of 20 tablets of each formulation was placed one by one in a digital durometer (THT-3, BIOBASE). The force (kgf) needed to cause the rupture was measured. The weight variation test was individually analyzed for 20 tablets of each formulation on an analytical balance (BBL31, Boeco) with sensitivity of $0.1 \mathrm{mg}$. The mean values and standard deviation of each test were calculated using Microsoft Excel 2007.

Drug content was measured as follows. The phenytoin tablets ( $n=20)$ were individually weighed, ground to fine powder, and a powder amount equivalent to $100 \mathrm{mg}$ of sodium phenytoin was weighed and added to a $100 \mathrm{~mL}$ volumetric flask. Then, $5 \mathrm{~mL}$ of methanol was added to the flask, mixed, and subjected to the ultrasound bath action (UCP-10 ultrasonic cleaner, Lab Companion) for $10 \mathrm{~min}$. The volume was completed to $100 \mathrm{~mL}$ with distilled water, then $25 \mathrm{~mL}$ of filtrate was diluted to $100 \mathrm{~mL}$ with a mixture of methanol and water (1:2). It was filtered through a 0.45 $\mu \mathrm{m}$ porosity filter, discarding the first $5 \mathrm{~mL}$ of the filtrate. The absorbances were then read at a wavelength of 205 $\mathrm{nm}$ using UV/Vis spectrophotometers (50 BIO, Varian). A calibration curve with a $R^{2}$ value of 0.992 was applied to calculate the concentration and drug content percentage.

- 


\section{Dissolution Profile}

To perform the dissolution profile, 12 tablets were used for each formulation (reference, T-1, T-2) and USP dissolution apparatus 2 (paddle), with a study time of 90 minutes, rotation speed: $75 \mathrm{rpm}$, dissolution medium temperature: $37 \pm 0.5{ }^{\circ} \mathrm{C}$, dissolution medium volume: $900 \mathrm{~mL}$ of HCl, $\mathrm{pH} 1.2$, buffer acetate $\mathrm{pH} 4.5$, or phosphate buffer $\mathrm{pH} 6.8$, and an eight-vessel dissolution tester (EDT 08LX, Electrolab). The deaeration of the medium was carried out by applying vacuum and filtering through a $0.45 \mu \mathrm{m}$ membrane filter while sonicating with a water bath.

The $5 \mathrm{~mL}$ samples were extracted through $0.45 \mu \mathrm{m}$ chromafil filters at the pre-established times of 5, 10, 15, $30,45,60$, and 90 minutes without medium replacement, based on the FDA guidance (21).

The absorbances were determined by UV/Vis spectrophotometry at a wavelength of $205 \mathrm{~nm}$, and fresh medium was used as blank (6). A calibration curve $(0.8$, $0.16,0.20,0.24,0.28,0.32$, and $0.36 \mathrm{mg} / \mathrm{mL}$ ) was applied with an $R^{2}$ value of 0.992 to calculate the concentration and percentage of drug content.

\section{Statistical Analysis}

Statistical analyses were performed with the GraphPad Prism software, version 5.00, and Microsoft Excel 2007 was used for data organization and to calculate standard deviation, coefficient of variation (CV), similarity and difference factors, DE\%, MDT, and AUC. As a statistical indicator of in vitro therapeutic equivalence, the similarity factor was used $(1,22,23)$. In addition, the AUC was calculated by the trapezius method $\left(\mathrm{AUC}_{0}{ }^{\mathrm{t}}\right)(3,24)$. From these values, DE and MDT were calculated $(1,3,25,26)$. The Dunnett method compared the reference formulation (control) with the other formulations and gave the values of $p$; a $p$-value less than 0.05 was considered significant.

\section{RESULTS}

Table 1 shows the trial of the formulations tested. The phenytoin reference tablets and generic tablets had similar weight $(p=0.07)$. The hardness test was performed because it is a factor that influences the dissolution of the tablets (27). The reference product had a mean hardness of $7.51 \mathrm{kgf}( \pm 0.0945 \mathrm{SD})$, which was statistically significantly different from T-1 (7.54 $\pm 0.0507 \mathrm{kgf})$ and T-2 (7.48 $\pm 0.910 \mathrm{kgf})$. Drug content was $100 \%$ for all three formulations, which satisfies the USP criteria.

Table 2 reports the dissolution profile of the 100-mg phenytoin sodium tablets in the three $\mathrm{pH}$ levels, and none of the study samples released $85 \%$ of the active principle within 30 minutes (coefficient of variation, $>4 \%$ ), which does not meet the BCS criteria. The dissolution profiles of the three formulations were not significantly different.

Figure 1 shows the dissolution profiles of the two generic phenytoin formulations, at $\mathrm{pH} \mathrm{1.2,4.5,} \mathrm{and} \mathrm{6.8.} \mathrm{The}$ figures show a slow release process up to 45 minutes.

Table 1. Characteristics of 100-mg Phenytoin Immediate-Release Tablet Formulations $(n=20)$

\begin{tabular}{|c|c|c|c|c|c|c|c|c|}
\hline \multirow{2}{*}{ Study samples } & \multicolumn{3}{|c|}{ Weight (g) } & \multicolumn{3}{c|}{ Hardness (kgf)* } & \multirow{2}{*}{ Content } & \\
\cline { 2 - 9 } & Mean & \pm SD & CV & Mean & \pm SD & CV & & \\
\hline R & 0.21 & 0.0046 & 0.0213 & 7.51 & 0.0945 & 0.0126 & $100.00 \%$ & E0517 \\
\hline T-1 & 0.21 & 0.0066 & 0.0310 & 7.54 & 0.0507 & 0.0067 & $100.00 \%$ & E1017 \\
\hline T-2 & 0.21 & 0.0058 & 0.0276 & 7.48 & 0.0910 & 0.0122 & $99.99 \%$ & E0416 \\
\hline
\end{tabular}

*95\% confidence interval, according to Dunnett for the reference vs T1 was -0.09830 to 0.9830 and reference vs T2 was -0.02830 to 0.08830 . SD: standard deviation; CV: coefficient of variation.

Table 2. Percentage of Dissolution of 100-mg Phenytoin Immediate-Release Tablet Formulations

\begin{tabular}{|c|c|c|c|c|c|c|c|c|c|c|c|c|c|c|c|c|c|c|}
\hline \multirow{3}{*}{$\begin{array}{l}\text { Time } \\
(\min )\end{array}$} & \multicolumn{6}{|c|}{ pH 1.2} & \multicolumn{6}{|c|}{ pH 4.5} & \multicolumn{6}{|c|}{ pH 6.8} \\
\hline & \multicolumn{2}{|c|}{$\mathbf{R}$} & \multicolumn{2}{|c|}{ T-1 } & \multicolumn{2}{|c|}{$\mathrm{T}-2$} & \multicolumn{2}{|c|}{$\mathbf{R}$} & \multicolumn{2}{|c|}{$\mathrm{T}-1$} & \multicolumn{2}{|c|}{$T-2$} & \multicolumn{2}{|c|}{$\mathbf{R}$} & \multicolumn{2}{|c|}{ T-1 } & \multicolumn{2}{|c|}{$T-2$} \\
\hline & $\%$ & CV & $\%$ & CV & $\%$ & CV & $\%$ & CV & $\%$ & CV & $\%$ & CV & $\%$ & CV & $\%$ & CV & $\%$ & CV \\
\hline 5 & 15.5 & 0.19 & 20.8 & 0.16 & 13.3 & 0.19 & 6.9 & 0.18 & 19.6 & 0.25 & 17.6 & 0.07 & 32.7 & 0.41 & 21.8 & 0.17 & 18.1 & 0.24 \\
\hline 10 & 25.6 & 0.08 & 23.3 & 0.12 & 20.8 & 0.17 & 13.2 & 0.40 & 25.8 & 0.28 & 25.5 & 0.13 & 25.4 & 0.26 & 24.2 & 0.14 & 24.5 & 0.22 \\
\hline 15 & 34.3 & 0.24 & 27.5 & 0.10 & 26.4 & 0.14 & 21.6 & 0.39 & 35.4 & 0.22 & 40.0 & 0.16 & 28.1 & 0.16 & 30.6 & 0.15 & 38.9 & 0.41 \\
\hline 30 & 54.9 & 0.17 & 49.8 & 0.13 & 49.6 & 0.08 & 40.6 & 0.19 & 51.4 & 0.19 & 54.6 & 0.19 & 56.1 & 0.21 & 49.7 & 0.32 & 70.9 & 0.26 \\
\hline 45 & 75.5 & 0.17 & 69.4 & 0.07 & 65.9 & 0.05 & 62.4 & 0.15 & 65.6 & 0.18 & 64.5 & 0.11 & 81.3 & 0.13 & 60.6 & 0.31 & 85.4 & 0.17 \\
\hline 60 & 89.7 & 0.06 & 85.9 & 0.08 & 81.9 & 0.04 & 82.6 & 0.08 & 82.3 & 0.11 & 82.3 & 0.12 & 83.8 & 0.13 & 66.8 & 0.29 & 92.0 & 0.10 \\
\hline 90 & 100 & 0.00 & 100 & 0.00 & 100 & 0.00 & 100 & 0.00 & 100 & 0.00 & 100 & 0.00 & 100 & 0.00 & 100 & 0.00 & 100 & 0.00 \\
\hline
\end{tabular}




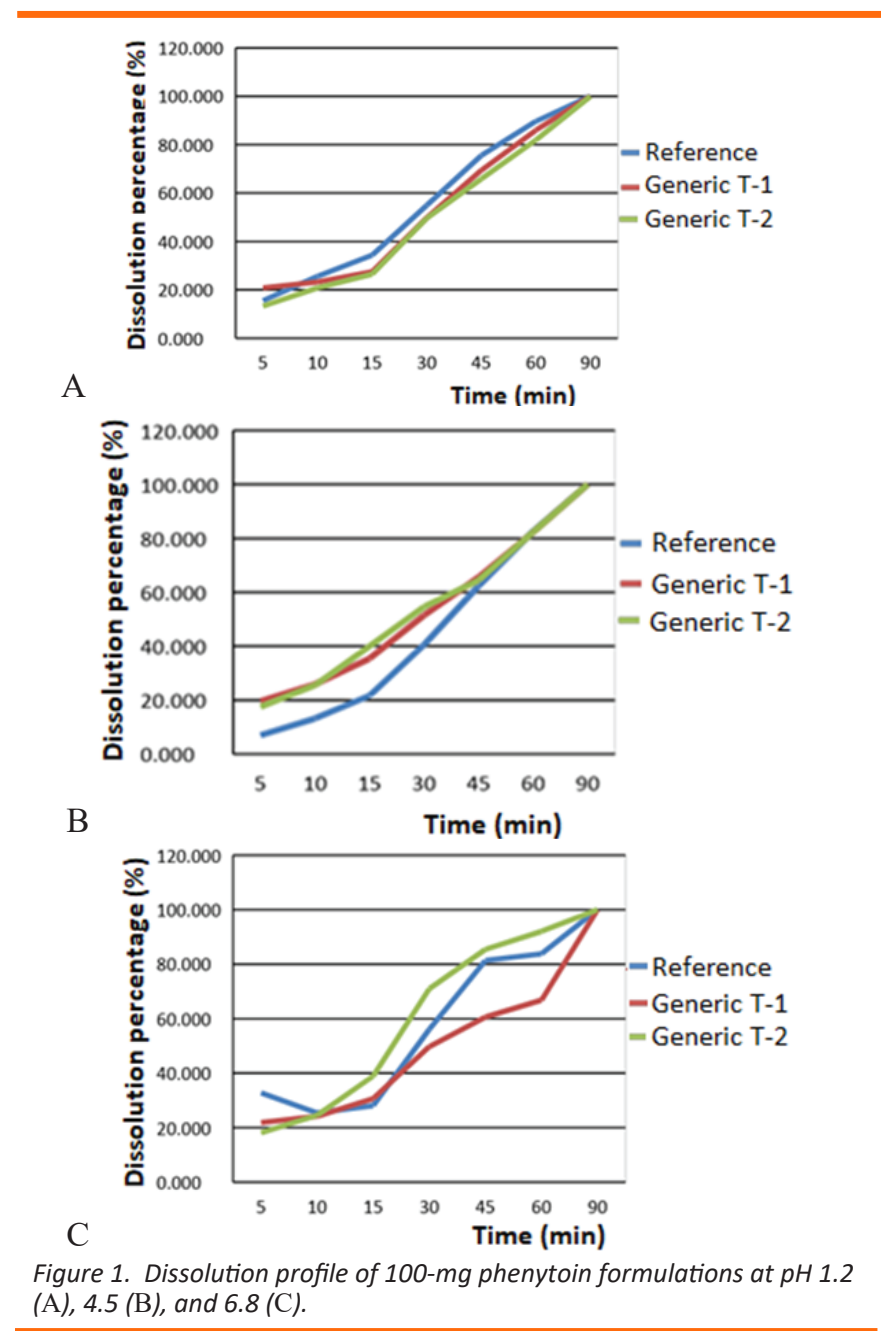

At $\mathrm{pH} 1.2$, the difference $\left(f_{1}\right)$ and similarity $\left(f_{2}\right)$ factors were 4.8 and 66.2 for T-1 and 9.5 and 60.3 for T-2, respectively, which are within the acceptance range $\left(f_{1}\right.$ : 0-15 and $\left.f_{2}: 50-100\right)$. At pH 4.5, T-1 $f_{1}$ was less than 0 (-16.1), reflecting a difference, which was confirmed an $f_{2}$ of 50.9. This indicates a $10 \%$ difference in the dissolution profile for T-1 compared to the reference. T-2 presented an $f_{1}$ of -17.4 and an $f_{2}$ of 48.5 , indicating a difference in the dissolution profiles of $-15 \%$ to $10 \%$. At pH $6.8, \mathrm{~T}-1$ and $\mathrm{T}-2$ did not meet the acceptance criteria. For the curves to be considered similar, $f_{1}$ must be close to 0 and the $f_{2}$ must be 100; a negative $f_{1}$ reflects the cumulative difference between both curves at all sampling points (Table 3).

At $\mathrm{pH} 1.2$, the reference product had an AUC value of 6023.7 during the 90-minute period, and the AUC values for T-1 and T-2 were 5717.8. At pH 4.5, the AUC values for T-1 and T-2 were higher compared to the reference. At pH 6.8, T-1 had a much lower AUC value than T-2 and the reference. As for the $\mathrm{DE}$, the reference product was 3.4\% higher than T-1 and T-2 t at pH 1.2 and 5-6\% lower at $\mathrm{pH}$ 4.5. At $\mathrm{pH} \mathrm{6.8,} \mathrm{DE} \mathrm{for} \mathrm{the} \mathrm{reference} \mathrm{product} \mathrm{was}$
9.2\% higher than T-1 and 5.5\% lower than T-2. Regarding $\mathrm{MDT}$, the reference product was 3.5 minutes less than T-1 and T-2 at $\mathrm{pH} 1.2$ and 5-6 minutes faster at $\mathrm{pH}$ 4.5. At $\mathrm{pH}$ $6.8, \mathrm{~T}-2$ had the lowest MDT (30.9 mins), followed by the reference (37.2 mins) and T-1 (46.5 mins). These results are presented in Table 4.

\section{DISCUSSION}

For the selection of the reference medicine, we have relied on the WHO guide, which indicates that first, a nationally available reference medicine should be chosen; second, the WHO reference list should be used; and third, look for a reference in the list of the International Conference on Harmonization (ICH). If none of the above are available, an appropriate reference (including a generic one) that has similar safety, quality, and effectiveness of the innovator can be used (1). For the present study, we used 100-mg sodium phenytoin tablets (bioequivalent LCh) from the Chile Laboratory as a reference, with relative bioavailability studies. According to the quality control results, the formulations investigated in weight and hardness were within the range of $\pm 5 \%$ SD for tablets with a mean weight of $0.21 \mathrm{~g}(p>0.05)$ and hardness of $7.48-7.54 \mathrm{kgf}(p<0.05)$. The drug content was within the acceptance range of $90-110 \%$ (99.99-100\%) according to USP 37; these tests should be performed before dissolution profile studies to ensure the quality of oral solid pharmaceutical forms meets the quality criteria of the USP and WHO $(1,2,14)$. Fretes et al. performed the quality controls according to the general criteria of the official pharmacopoeias prior to the dissolution profiles of lamotrigine (28). Grande-Ortiz et al. also performed the quality control tests of amoxicillin, doxycycline, and fluconazole before performing dissolution profiles (29). In a study conducted by Fonseca et al. they mention that the criteria for acceptance of hardness values must be $7.0-16.5 \mathrm{kgf}$ (27). In our study, we have found that hardness values are within that range. If the compression force is increased, the resistance to rupture (hardness) of the tablet is greater. The increase in compression force can cause lamination, affecting friability, disintegration time, and dissolution profiles (22). It is reported that if the hardness of the furosemide tablets is $8.0-12.0 \mathrm{kgf}$, the percentage of content is $101.2-100.1 \%$, respectively (22). Ghayas et al. mention that the formulation and manufacturing factors, the amount of disintegrant, lubricant, compression force, and mixing time influence the bioavailability of the drug (30). Alvarado et al. observed that the multisource tablets of digoxin encoded as TDF25 have a lower hardness value, indicating a low concentration of binder or a weak compression that can accelerate the dissolution profile (31). León et al. 
Table 3. Similarity $\left(f_{2}\right)$ and Difference $\left(f_{1}\right)$ Factors for Generic Products $(T-1, T-2)$ Compared to the Reference Product (Immediate-Release Tablets Containing 100-mg Phenytoin)

\begin{tabular}{|c|c|c|c|c|c|c|c|c|c|c|c|}
\hline \multicolumn{4}{|c|}{ pH 1.2 } & \multicolumn{4}{c|}{$\mathrm{pH} 4.5$} & \multicolumn{4}{c|}{$\mathrm{pH} 6.8$} \\
\hline$f_{1}$ & $f_{2}$ & $f_{1}$ & $f_{2}$ & $f_{1}$ & $f_{2}$ & $f_{1}$ & $f_{2}$ & $f_{1}$ & $f_{2}$ & $f_{1}$ & $f_{2}$ \\
\hline 4.8 & 66.2 & 9.5 & 60.3 & -16.1 & 50.9 & -17.4 & 48.5 & 13.2 & 47.4 & -5.5 & 48.5 \\
\hline $\mathrm{Y}$ & $\mathrm{Y}$ & $\mathrm{Y}$ & $\mathrm{Y}$ & $\mathrm{D}$ & $\mathrm{Y}$ & $\mathrm{D}$ & $\mathrm{N}$ & $\mathrm{Y}$ & $\mathrm{N}$ & $\mathrm{D}$ & $\mathrm{N}$ \\
\hline
\end{tabular}

$Y$ : within acceptable range; $N$ : not within acceptable range; $D: f_{1}<0$ reflects the cumulative difference between both curves at all sampling points.

Table 4. Parameters of Drug Release for Generic (T-1, T-2) and Reference (R) Products (Immediate-Release Tablets Containing 100-mg Phenytoin)

\begin{tabular}{|c|c|c|c|c|c|c|c|c|c|}
\hline \multirow{2}{*}{$\begin{array}{c}\text { Study } \\
\text { samples }\end{array}$} & \multicolumn{3}{|c|}{ pH 1.2} & \multicolumn{3}{|c|}{ pH 4.5} & \multicolumn{3}{|c|}{ pH 6.8} \\
\hline & $\begin{array}{c}\mathrm{AUC}_{\mathrm{o}}{ }^{\top} \\
(\mathrm{min} \%)\end{array}$ & $\begin{array}{l}\text { DE } \\
\text { (\%) }\end{array}$ & $\begin{array}{l}\text { MDT } \\
\text { ( } \mathrm{min})\end{array}$ & $\begin{array}{l}\mathrm{AUC}_{\mathrm{o}}^{\top} \\
\text { (min\%) }\end{array}$ & $\begin{array}{l}\text { DE } \\
(\%)\end{array}$ & $\begin{array}{l}\text { MDT } \\
\text { (min) }\end{array}$ & $\begin{array}{l}A^{A U C_{o}{ }^{\top}} \\
\text { (min\%) }\end{array}$ & $\begin{array}{l}\text { DE } \\
(\%)\end{array}$ & $\begin{array}{l}\text { MDT } \\
\text { (min) }\end{array}$ \\
\hline $\mathbf{R}$ & 6023.7 & 66.9 & 36.4 & 5221.3 & 57.9 & 45.5 & 6018.4 & 66.9 & 37.2 \\
\hline$T-1$ & 5717.8 & 63.5 & 39.9 & 5688.5 & 63.2 & 40.2 & 5193.9 & 57.7 & 46.5 \\
\hline$T-2$ & 5717.8 & 63.5 & 39.9 & 5754.9 & 63.9 & 39.3 & 6519.5 & 72.4 & 30.9 \\
\hline
\end{tabular}

T: trapezius method; DE: dissolution efficiency; MDT: mean dissolution time.

reported that the hardness values of paracetamol tablets are variable (9.35-15.35 kgf), indicating that those of lower value have little binder or weak compression, and those with high values have a greater amount of binder or have a higher compression, which can increase or delay the dissolution process, respectively (32).

For oral solid immediate-release dosage forms that dissolve rapidly, with an average of $85 \%$ or more in 30 minutes, USP apparatus 1 at $100 \mathrm{rpm}$ is used for capsules and products that tend to float; and USP Apparatus 2 is used at 50-75 rpm for tablets when properly justified at $\mathrm{pH} 1.2,4.5$, and $6.8(2,20)$. At the same time, the USP 37 NF 32 suggests using apparatus 2 for chewable tablets (2). In this regard, we have relied on both documents to use apparatus 2 in our study. According to the FDA guide, a quality control test can be done for highly soluble and rapidly dissolving drugs, taking a single point of dissolution; if two points are taken, it is to characterize the quality and as a control of quality of slowly dissolving or water-soluble drugs (e.g., carbamazepine). Dissolution profiles are made to accept the equality of medicines, to exempt from in vivo bioequivalence studies, and to support in vitro bioequivalence studies. In the present study, the dissolution profiles of the two formulations of the phenytoin generic tablets and their reference were analyzed in three dissolution media that simulate the gastrointestinal tract ( $\mathrm{pH} 1.2,4.5$, and 6.8).

The World Health Organization (WHO) considers class 2 drugs (low solubility and high permeability) for in vitro bioequivalence studies, meeting the following requirements (6): 1) When permeability is not a limitation, weak acidic drugs are highly soluble at $\mathrm{pH}$
6.8 (85\% or more in 30 minutes or less) where the nonionized form predominates, therefore, it will have good absorption because it will be in an area with a larger surface area for absorption; 2) when they have the same dissolution profiles in the three media at $\mathrm{pH} 1.2$, 4.5 , and 6.8 , determined with the value of $f_{2}$; and 3 ) when the excipients of the generic medication should be evaluated in type and quantity of surfactants. Class 2 drugs have variable bioavailability; carbamazepine, sodium phenytoin, glibenclamide, ketoprofen, naproxen, and others belong to this class $(6,33)$.

Class 4 drugs cannot be exempted from in vivo bioavailability and bioequivalence studies because they are drugs that have low solubility and low permeability, that is, they are not absorbed very well through the intestinal membrane. Furosemide, hydrochlorothiazide, taxol, and others belong to this class $(6,33)$. Both $\mathrm{WHO}$ and the FDA consider bio-exemption to perform bioequivalence studies in vitro for solid oral dosage forms with immediate release of class 1 and 3 drugs based on the BCS criteria $(6,20,33,34)$. The drugs found in class 1 are of high solubility and high permeability, so the generic and reference medicines have to release more than $85 \%$ of the active substance in 30 minutes. In this case, the rate of gastric emptying becomes the determining stage of the absorption rate, and the excipients do not significantly affect the bioavailability of the drug; to this group belongs diltiazem, metoprolol, propranolol, verapamil, and others. Medications containing class 3 drugs (high solubility and low permeability) should dissolve rapidly ( $\geq 85 \%$ in $15 \mathrm{~min}$ ), at all physiological pH levels. In this case, the physiological alteration and the permeability 
through biological membranes is the limiting step of the speed of drug absorption, so the drug's bioavailability is variable; the release of the active principle does not depend on the pharmaceutical form. In addition, the multisource medicine must contain the same excipients as the reference medicine, so that the excipients do not influence absorption, have the same dose, and the same pharmaceutical form. To this class belongs acyclovir, metformin, ranitidine, and others (20). In our study, the percentage of dissolution observed in the three media was less than $85 \%$ in after 30 minutes, which did not meet the criteria for bio-exemption $(34,35)$. However, the optimal dissolution profile was found to be $\mathrm{pH} 1.2$, which is predictable because phenytoin has a pKa of 8.3, and in an acidic medium (stomach $\mathrm{pH}$ 1.5) phenytoin is in its non-ionized form, which is corroborated with the equation, $\mathrm{pKa}-\mathrm{pH}=\mathrm{fu} / \mathrm{fi}$, where $\mathrm{fu}$ is the non-ionized fraction and $f i$ is the ionized fraction of the drug. ANOVA and Dunnett's method were used to statistically verify that dissolution of all formulations was not significantly different $(p>0.05)$.

The variation of the dissolution profiles in this study may be due to the dissolution medium or to the manufacturing and formulation processes. Regarding the dissolution medium, Markopoulos et al. mention that $\mathrm{pH}$ is a determining element of the solution (36). Dressman et al. explained that the change in $\mathrm{pH}$ affects the solubility of the drugs and, therefore, in their oral bioavailability; whereas Krieg et al. demonstrated that the dissolution medium influences the release and dissolution of the drug $(37,38)$. Also, the amount and type of excipient, the manufacturing process, or both, influence the dissolution profile (1). Block et al. demonstrated this in a study of dissolution of metformin tablets; and Battu et al. demonstrated that disintegrating and superdisintegrating excipients (crosslinked polymers that swell in contact with water) influence the disintegration process $(39,40)$. Although the correlation of the solution with absorption and bioavailability is not well established, many researchers state that the solution is a limiting factor of bioavailability and influences the pharmacological response $(41,42)$. The similarity factor is used to determine the in vitro therapeutic equivalence of the multisource drugs $(1$, 36). At $\mathrm{pH}$ similar to the gastrointestinal tract $(\mathrm{pH} \mathrm{1.2),}$ the generic formulations in our study (T-1 and T-2) had an $f_{2}$ value greater than 50 , which indicates similarity of dissolution performance in the acid medium. At pH 4.5, the $f_{2}$ value of T-1 exceeded 50 and T-2 was less than 50 . At $\mathrm{pH} 6.8$, both $\mathrm{T}-1$ and $\mathrm{T}-2$ had an $f_{2}$ value less than 50 , indicating a difference in the dissolution performance in the phosphate medium. Additionally, we measured
$D E$, the value of which must be greater than $50 \%$ for immediate-release drugs $(12,15)$., In our study, we obtained a value of $63.5 \%$ for the two generic products and $66.9 \%$ for the reference product in the acidic medium (pH 1.2), which represents the degree of absorption of the drug in vivo based on its two variables: the concentration of the drug in the solution and the contact with the gastric mucosa where absorption will begin, and MDT indicates the residence time of the drug in the solid state in the dissolution medium $(12,15)$.

Bioavailability and bioequivalence studies should be carried out in drugs with a narrow therapeutic range, such as phenytoin, which has a minimum effective concentration of $10 \mathrm{mg} / \mathrm{L}$ and an effective maximum of $20 \mathrm{mg} / \mathrm{L}$ (43-45). In this sense, a poor solution or a small change in the dose would lead to changes in bioavailability and plasma levels (46). At the same time, because these types of drugs form strong bonds with plasma proteins (i.e., albumin), they are displaced from binding with usual proteins by drugs that have a higher affinity for those proteins, which generates toxicity when the maximum concentration is exceeded (45). It is also known that phenytoin is metabolized by CYP2C9, and patients who are slow metabolizers are more likely to have toxicity (47). In this regard, it is proposed to conduct relative bioavailability studies to demonstrate therapeutic equivalence and interchangeability in clinical practice.

\section{CONCLUSIONS}

Based on similar factor analysis, the present study revealed differences in the dissolution performance of generic and reference formulations of immediate-release phenytoin tablets $(100 \mathrm{mg})$ at $\mathrm{pH} 4.5$ and 6.8 , but the formulations were considered to be therapeutically equivalent in vitro at $\mathrm{pH}$ 1.2. It is recommended to perform relative bioavailability studies for phenytoin and other drugs that have a narrow therapeutic margin.

\section{FUNDING}

This work was supported by the Peruvian Association of Immunogenomics and Personalized Medicine.

\section{CONFLICTS OF INTEREST}

The authors disclosed no conflicts of interest related to this article.

\section{REFERENCES}

1. Villarroel Stuart, A.; Clement, Y.; Sealy, P.; Löbenberg, R.; Montane-Jaime, L.; Maharaj, R. G.; Maxwell, A. Comparing the dissolution profiles of seven metformin formulations in simulated intestinal fluid. Dissolut. Technol. 2015, 22, 17-21. DOI: 10.14227/DT220115P17. 
2. The United States Pharmacopeia and National Formulary USP 37-NF 32; The United States Pharmacopeial Convention, Inc.: Rockville, MD, 2014.

3. Matiz, G.; Trujillo, M.; Pérez, D.; Baena, Y. In vitro evaluation of the interchangeability of different brands of diclofenac sodium tablets available in the Colombian market [in Spanish]. Biomédica. 2018, 38, 486-495. DOI: 10.7705/biomedica. v38i4.3988.

4. Ponce, L.; Jaramillo, A. Estudio de bioequivalencia in vitro de cuatro productos de amoxicilina del mercado colombiano. Rev. Colomb. Cienc. Quím. Farm. 2004, 44, 282-310.

5. Alvarado Yarasca, A.; Salazar Granara, A.; Pineda Perez, N.; Villanueva Vilchez, H.; Cáceres Andonaire, E. Estudio de la biodisponibilidad relativa de una formulación multifuente de sulfametoxazol respecto al medicamento referente. Horiz. Med. (Lima). 2016, 16, 12-19. DOI: 10.24265/horizmed.2016. v16n3.03.

6. WHO Expert Committee on Specifications for Pharmaceutical Preparations. Multisource (generic) pharmaceutical products: guidelines on registration requirements to establish interchangeability; WHO Technical Report Series, No. 937, Annex 7; World Health Organization: Geneva, 2006; pp 347438.

7. Baena, Y.; Ponce, L. Importancia y fundamentación del sistema de clasificación biofarmacéutico, como base de la exención de estudios de biodisponibilidad y bioequivalencia in vivo. Rev. Colomb. Cienc. Quím. Farm. 2008, 37, 18-32.

8. Bioavailability and Bioequivalence Studies for Orally Administered Drug Products-General Considerations; Guidance for Industry; U.S. Department of Health and Human Services, Food and Drug Administration, Center for Drug Evaluation and Research (CDER), U.S. Government Printing Office: Washington, DC, 2003.

9. Nainar, S.; Rajiah, K.; Angamuthu, S.; Prabakaran, D.; Kasibhatta, R. Biopharmaceutical Classification System in in vitro/ in vivo Correlation: Concept and Development Strategies in Drug Delivery. Trop. J. Pharm. Res. 2012, 11, 319-329. DOI: 10.4314/ tjpr.v11i2.20.

10. Mahesh Kumar, K.; Anil, B. Biopharmaceutics drug disposition classification system: An extensión of Biopharmaceutics Classification System. Int. Res. J. Pharm. 2012, 3, 5-10.

11. Maddy, O. Studying the effect of dispersed drug crystal in the organic phase on the encapsulation by solvent evaporation technique, (3) Independent models as tools for studying the drug release profiles. World J. Pharm. Sci. 2014, 2, 409-421.

12. Jung, H.; De Anda, G.; Rubio, K.; Mayet, L. Comparación de perfiles de disolución. Impacto de los criterios de diferentes agencias regulatorias en el cálculo de $f_{2}$. Rev. Mex. Cienc. Farm. 2012, 43, 67-71.

13. Tabbakhian, M.; Hasanzadeh, F.; Tavakoli, N.; Jamshidian, Z. Dissolution enhancement of glibenclamide by solid dispersion: solvent evaporation versus a supercritical fluid-based solvent -antisolvent technique. Res Pharm. Sci. 2014, 9, 337-350.
14. World Health Organization. Fortieth report. Annex 8: Proposal to waive in vivo bioequivalence requirements for WHO model list of essential medicines inmediate-release, solid oral dosage forms. Geneva: WHO; 2006.

15. National Institute for Food and Drug Surveillance, INVIMA website. https://www.invima.gov.co/images/bioequivalencia/ Sistema-de-clasificacion-biofarmaceutica-para-los-principiosactivos-que-deben-presentar-estudios-de-bioequivalenciade-acuerdo-con-el-anexo-tecnico-2-de-la-resolucion-1124de-2016.pdf (accessed February 26, 2019).

16. National Single Request for Essential Medicines for the Health Sector. Ministerial Resolution No. 1361-2018 / MINSA. Republic of Peru, Ministry of Health. December 28, 2019.

17. El-Sabawi, D.; Abbasi, S.; Alja'fari, S.; Hamdan, I. Pharmaceutical evaluation of glibenclamide products available in the Jordanian market. Afr. J. Pharm. Pharmacol. 2013, 7, 1464-1470. DOI: 10.5897/AJPP2012.0014.

18. O'Hara, T.; Dunne, A.; Butler, J.; Devane, J. A review of methods used to compare dissolution profile data. Pharm. Sci. Technol. Today 1998, 1, 214-223. DOI: 10.1016/S1461-5347(98)00053-4.

19. Shah, V. P.; Tsong, Y.; Sathe, P.; Liu, J. P. In vitro dissolution profile comparison--statistics and analysis of the similarity factor, $f_{2}$. Pharm. Res. 1998, 15, 889-896. DOI: 10.1023/A:1011976615750.

20. Waiver of In Vivo Bioavailability and Bioequivalence Studies for Immediate-Release Solid Oral Dosage Forms Based on a Biopharmaceutics Classification System; Guidance for Industry; U.S. Department of Health and Human Services, Food and Drug Administration, Center for Drug Evaluation and Research (CDER), U.S. Government Printing Office: Washington, DC, 2017.

21. Dissolution Testing of Immediate Release Solid Oral Dosage Forms; Guidance for Industry; U.S. Department of Health and Human Services, Food and Drug Administration, Center for Drug Evaluation and Research (CDER), U.S. Government Printing Office: Washington, DC, 1997.

22. Matiz Melo, G. E.; Rodríguez Cavallo, E. Comparative study of the biopharmaceutical quality of commercial and generic brands of captopril and losartan tablets in the Colombian market [in Spanish]. Rev. Colomb. Ciencias Quim. Farm. 2014, 43, 217-233. DOI: 10.15446/rcciquifa.v43n2.54209.

23. Franco, L. A.; Matiz, G. E.; Pájaro, I. Estudio biofarmacéutico comparativo de marcas comerciales de tabletas de ciprofloxacino disponibles en el mercado colombiano. Rev. Salud Publica (Bogota) 2012, 14, 695-709.

24. Podczeck, F. Comparison of in vitro dissolution profiles by calculating mean dissolution time (MDT) or mean residence time (MRT). Int. J. Pharm. 1993, 97, 93-100. DOI: 10.1016/03785173(93)90129-4.

25. Costa, P.; Sousa Lobo, J. M. Modeling and comparison of dissolution profiles. Eur. J. Pharm. Sci. 2001, 13, 123-133. DOI: 10.1016/S0928-0987(01)00095-1.

26. Medina, J.; Hurtado, M.; Cortés, A.; Domínguez, A. Disolución comparativa de indometacina en cápsulas utilizando los 
Aparatos 1 y 4 USP. Rev. Mex. Cienc. Farm. 2012, 43, 72-80.

27. Fonseca, J.; Garzón, P. Efecto de la fuerza de compresión sobre los atributos críticos de calidad en tabletas de liberación inmediata de furosemida. Rev. Colomb. Cienc. Quím. Farm. 2017, 46, 235-255.

28. Fretes de Aquino, S. L.; Vázquez Mesa, M.; Lugo Rodriguez, G. B. Comparative evaluation between dissolution profiles of similar 25mg Lamotrigine tablets and the innovative drug, marketed in Paraguay [in Spanish]. Mem. Inst. Investig. Science Health. 2016, 14, 53-60. DOI: 10.18004/Mem.iics/18129528/2016.014(02)53-060.

29. Grande-Ortiz, M.; Taipe-Cadenillas, S.; Villodas-Saldaña, C.; Rodríguez-Calzado, J.; Moreno-Exebio, L. Therapeutic equivalence evaluated by in vitro studies of multisource pharmaceutical products: case studies of amoxicillin, doxycycline and fluconazole in Lima, Peru [in Spanish]. Rev. Peru. Med. Exp. Salud Publica 2019, 36, 74-80. DOI: 10.17843/ rpmesp.2019.361.3912.

30. Ghayas, S.; Sheraz, M. A.; Anjum, F.; Baig, M. T. Factors influencing the dissolution testing of drugs. Pak. J. Health Res. 2013, 1, 1-11.

31. Alvarado Yarasca, A.; Lozada Colque, G. L.; Llerena Benites, R. C.; Macavilca Francia, S. X.; Marcos Eguizabal, C. E.; Pisconte Campos, N. C.; Poma Ghiggo, J. A.; Ismodes Noor, H. S. Y. Determination of therapeutic range and study of biopharmaceutical equivalence of two multisource Digoxin tablets of $0.25 \mathrm{mg}$ [in Spanish]. Horiz. Med. (Lima). 2014, 14, 48-45.

32. León, G.; Osorio, M.; Matiz, G. Estudio biofarmacéutico comparativo de tabletas de acetaminofén $500 \mathrm{mg}$ disponibles en el mercado colombiano. Rev. Cuba. Farm. 2015, 49, 630-640.

33. Tsume, Y.; Mudie, D. M.; Langguth, P.; Amidon, G. E.; Amidon, G. L. The Biopharmaceutics Classification System: subclasses for in vivo predictive dissolution (IPD) methodology and IVIVC. Eur. J. Pharm. Sci. 2014; 57, 152-163. DOI: 10.1016/j.ejps.2014.01.009.

34. Yu, L. X.; Amidon, G. L.; Polli, J. E.; Zhao, H.; Mehta, M. U.; Conner, D. P.; Shah, V. P.; Lesko, L. J.; Chen, M. L.; Lee, V. H.; Hussain, A. S. Biopharmaceutics classification system: the scientific basis for biowaiver extensions. Pharm. Res. 2002, 19, 921-925. DOI: 10.1023/A:1016473601633.

35. Stavchansky, S. Scientific perspectives on extending the provision for waivers of in vivo bioavailability and bioequivalence studies for drug products containing high solubility-low permeability drugs (BCS-Class 3). AAPS J. 2008, 10, 300-305. DOI: 10.1208/s12248-008-9030-y.

36. Markopoulos, C.; Andreas, C. J.; Vertzoni, M.; Dressman, J.; Reppas, C. In-vitro simulation of luminal conditions for evaluation of performance of oral drug products: Choosing the appropriate test media. Eur. J. Pharm. Biopharm. 2015, 93, 173-182. DOI: 10.1016/j.ejpb.2015.03.009.
37. Dressman, J. B.; Berardi, R. R.; Dermentzoglou, L. C.; Russell, T. L.; Schmaltz, S. P.; Barnett, J. L.; Jarvenpaa, K. M. Upper gastrointestinal (GI) $\mathrm{pH}$ in young, healthy men and women. Pharm. Res. 1990, 7, 756-761. DOI: 10.1023/A:1015827908309.

38. Krieg, B. J.; Taghavi, S. M.; Amidon, G. L.; Amidon, G. E. In vivo predictive dissolution: comparing the effect of bicarbonate and phosphate buffer on the dissolution of weak acids and weak bases. J. Pharm. Sci. 2015, 104, 2894-2904. DOI: 10.1002/ jps. 24460 .

39. Block, L. C.; Schemling, L. O.; Couto, A. G.; Mourão, S. C.; Bresolin, T. M. B. Pharmaceutical equivalence of metformin tablets with various binders. Rev. Cienc. Farm. Basica Apl. 2008 29, 29-35.

40. Battu, S. K.; Repka, M. A.; Majumdar, S.; Madhusudan, R. Y. Formulation and evaluation of rapidly disintegrating fenoverine tablets: effect of superdisintegrants. Drug Dev. Ind. Pharm. 2007, 33, 1225-1232. DOI: 10.1080/03639040701377888.

41. Kostewicz, E. S.; Abrahamsson, B.; Brewster, M.; Brouwers, J.; Butler, J.; Carlert, S.; Dickinson, P. A.; Dressman, J.; Holm, R.; Klein, S.; Mann, J.; McAllister, M.; Minekus, M.; Muenster, U.; Müllertz, A.; Verwei, M.; Vertzoni, M.; Weitschies, W.; Augustijns, P. In vitro models for the prediction of in vivo performance of oral dosage forms. Eur. J. Pharm. Sci. 2014, 57, 342-366. DOI: 10.1016/j.ejps.2013.08.024.

42. Tarawneh, O.; Madi, A.; Hamed, R.; Qirem, R.; Qerem, W.; Alhusban, A.; Sunoqrot, S.; Mahmoud, N.; Ata, S.; Alsheikh, I. In vitro Characterization and Evaluation of Commercialized Paracetamol Products in Jordan. Dissolut. Technol. 2019, 26, 36-44. DOI: 10.14227/DT260119P36.

43. Saavedra, I. S.; Iturriaga, V. V.; Ávila, L. M.; Quiñones, L. S. Biowaiver studies (in vitro) to establish equivalence of drugs [in Spanish]. Cuad. Méd. Soc. (Chile). 2011, 51, 66-79.

44. Escobar, L. Therapeutic drug monitoring and practical aspects of pharmacokinetics [in Spanish]. Rev. Med. Clin. Condes. 2016, 27, 605-614. DOI: 10.1016/j.rmclc.2016.09.006.

45. Thaker, S. J.; Gandhe, P. P.; Godbole, C. J.; Bendkhale, S. R.; Mali, N. B.; Thatte, U. M.; Gogtay, N. J. A prospective study to assess the association between genotype, phenotype and Prakriti in individuals on phenytoin monotherapy. J. Ayurveda Integr. Med. 2017, 8, 37-41. DOI: 10.1016/j.jaim.2016.12.001.

46. Kim, H.; Fang, L.; Yu, J.; Meng, Z.; Trame, M. N.; Schmidt, S.; Lesko, L. J.; Zhao, L. Is Bioequivalence established based on the reference-scaled average bioequivalence approach relevant to chronic administration of phenytoin? Perspectives based on population pharmacokinetic modeling and simulations. J. Clin. Pharmacol. 2019, 59, 1061-1069. DOI: 10.1002/jcph.1380.

47. Alvarado, A. T.; Muñoz, A. M.; Loja, B.; Miyasato, J. M.; García, J. A.; Cerro, R. A.; Quiñones, L. A.; Varela, N. M. Estudio de las variantes alélicas CYP2C9*2 y CYP2C9*3 en muestras de población mestiza peruana. Biomedica 2019, 39, 601-610. DOI: 10.7705/biomedica.4636. 